\title{
Disaggregating lone-actor grievance-fuelled violence: Comparing lone-actor terrorists and mass murderers
}

\author{
Caitlin Clemmow $^{1}$, Paul Gill ${ }^{1}$, Noémie Bouhana ${ }^{1}$, James Silver ${ }^{2}$, John Horgan $^{3}$ \\ ${ }^{1}$ University College London, Department of Security and Crime Science \\ ${ }^{2}$ Worcester University, Department of Criminal Justice \\ ${ }^{3}$ Georgia State University, Global Studies Institute and Department of Psychology
}

Correspondence: Caitlin Clemmow, Department of Security\& Crime Science, University College London, 35Tavistock Square, Kings Cross, London, WC1H9EZ, U.K. Email: c.clemmow.17@ucl.ac.uk

Caitlin Clemmow is a third-year $\mathrm{PhD}$ student at University College London's Department of Security and Crime Science. Her research focusses on detecting dynamic patterns across a spectrum of grievance-fuelled violence to enhance the threat assessment of these types of offenders. She works as a research assistant on the ERC-funded Grievance project (see below).

Paul Gill is a Professor at University College London's Department of Security and Crime Science. He has over 60 publications on the topic of terrorist behaviour. He has conducted research funded by the Office for Naval Research, the Department of Homeland Security, DSTL, the European Union, the National Institute of Justice, CREST and MINERVA. These projects focused upon various aspects of terrorist behaviour including IED development, creativity, terrorist network structures, and lone-actor terrorism. He currently leads the ERCfunded Grievance project https://www.grievance-erc.com.

Noémie Bouhana is an Associate Professor of Security and Crime Science at University College London. Her research centres on the social ecological processes involved in radicalisation, as well as the mechanisms which underpin individual vulnerability to moral change. She has conducted research funded by the Defence Science and Technology Laboratory, the Office of Security and Counter-Terrorism, the UK Centre for Research and Evidence on Security Threats, the National Institute of Justice, and Public Safety Canada. Most recently, she led the $€ 3 \mathrm{M}$, EU-funded FP7 PRIME project on lone actor terrorism. At present, she directs the \$1M MINERVA project “The Social Ecology of Radicalisation”.

James Silver, Phd, JD is an assistant professor of criminal justice at Worcester State University. He focuses his research on public mass casualty events, terrorism, and threat assessment.

John Horgan is a Distinguished University Professor at Georgia State University's Department of Psychology where he directs the Violent Extremism Research Group (VERG). His work is widely published, with books including The Psychology of Terrorism (now in its second edition and published in over a dozen languages worldwide. He is Editor of the journal Terrorism and Political Violence and Consulting Editor of American Psychologist. 
He is a member of the Research Working Group of the FBI's National Centre for the Analysis of Violent Crime.

\section{Acknowledgements}

We would like to acknowledge funding that previously supported collection of the data employed here, without which the present study would not have been possible. First, we thank the National Institute for Justice which supported the collating of the mass murder data. Second, we thank the European Commission 7th Framework Programme which supported updating of the lone-actor terrorist data and the development of the RAF. 


\title{
Disaggregating lone-actor grievance-fuelled violence: Comparing lone-actor terrorists and mass murderers
}

\begin{abstract}
Research suggests that lone-actor terrorists and mass murderers may be better conceptualised holistically, as lone-actor grievance-fuelled violence offenders. The present study sought to examine the extent to which these offenders could (or could not) be disaggregated along dimensions particularly relevant to the threat assessment of both. Drawing on a previously developed Risk Analysis Framework (RAF), the offending process was theorised as interactions among propensity, situation, preparatory, leakage and network indicators. We analysed a dataset of 183 US offenders, including 68 lone-actor terrorists and 115 solo mass murderers. Cluster analysis identified profiles within each of the components. Bi-variate analysis examined the extent to which these profiles classified offenders previously labelled as lone-actor terrorists or mass murderers. Lastly, we propose a model of lone-actor grievance-fuelled violence. The results suggest that whilst differences may exist at the periphery of these dimensions, the degree of shared space is noteworthy. Moreover, no profile classifies a single 'type' of offender exclusively. These findings are discussed in terms of the implications for the threat assessment and management of lone-actor grievance-fuelled violence offenders.
\end{abstract}

\section{Keywords}

Lone-actor, terrorism, mass murder, LAGFV, risk analysis framework 


\section{Introduction}

Lone-actor grievance-fuelled violence (LAGFV) describes different types of offenders, including mass murderers, lone-actor terrorists, school shooters, workplace shooters, and other types of demonstrative violence. Previous research suggests that these offenders may share a common genesis ${ }^{1}$. Therefore, this type of violence may be better conceptualised generally, rather than as distinct 'types'.2 In an article for the Washington Post, former director of the National Counterterrorism Centre and senior fellow of the Combating Terrorism Centre, Leiter and Sheehan, ${ }^{3}$ advised that we should "treat mass shootings the way we treated terrorism", calling for fusion organisations and an intelligencegathering approach. Recently, the Department of Homeland Security (DHS) ${ }^{4}$ announced the establishment of a new office for Targeted Violence and Terrorism Prevention. Hence there is an impetus for both research and policy to reconceptualise these offences as variants of LAGFV, rather than as distinct types. Establishing the extent to which these offenders share commonalities (or not), could inform a general threat assessment framework that may benefit analysts and other practitioners. The present study aims to identify if and how these offenders differ, and offer insights into why.

Various studies have examined the conceptual boundaries between different types of LAGFV. These include comparisons of suicide terrorists with rampage, workplace and school shooters, ${ }^{5}$ suicide terrorists with mass shooters, ${ }^{6}$ ideologically and non-ideologically motivated mass public shooters, ${ }^{7}$ political and non-political murderers in Northern Ireland ${ }^{8}$, adolescent targeted school attacks with jihadi terrorists attacks in Germany, ${ }^{9}$ both far-right homicides, ${ }^{10}$ and European lone-actor terrorists with 'common' homicides, ${ }^{11}$ and lone-actor terrorists with mass murderers. ${ }^{12}$ Most of these studies consistently report similar profiles of psychological and social characteristics, providing evidence for conceptualising these offenders as types of LAGFV. 
Many studies examine a number of factors associated with these types of violence, singly. This is the basis of much important research which forms the rationale for our study. However, we suggest a more nuanced understanding may be gleaned from now considering the relevance of patterns of indicators. In fact, Thompson, Stewart \& Dennison ${ }^{13}$ demonstrated just this. In a content analysis of 43 stalking court transcripts, the authors found that combining multiple risk factors provided a more sophisticated understanding of stalking violence than considering indicators independently. We suggest that such an approach is appropriate to conceptualising LAGFV, and thus adopt a strategy to examine configurations of indicators which previous research has demonstrated to be multifinal. ${ }^{15}$

The present study utilises cluster analysis to explore the extent to which an aggregate dataset of solo mass murderers and lone-actor terrorists, can be disaggregated. Hence, we propose to examine the usefulness of these labels in describing what previous research contends are different presentations of the same phenomenon. Rather than presuming two a priori categories and comparing them, we aggregate two existing datasets and seek to inductively extract patterns embedded within the data. We examine 115 mass murders and 68 lone-actor terrorists. First, we conceptualise the offending process as interactions among propensity, situation, preparatory, network and leakage factors. We use cluster analysis to detect sets of cases that share attributes within each of these components. We then examine the extent to which these profiles classify offenders previously labelled as lone-actor terrorists or mass murderers. Second, we use bi-variate analysis to establish the extent to which the theorised components are associated, and propose a model of LAGFV. Our analysis finds support for conceptualising these offenders generally. At the periphery, we note significant differences, however many of these offenders ocupy a shared space across multiple dimensions directly relevant to threat assessment. 


\section{Background}

First, we describe the analytical framework adopted as theoretical guidance; the RAF. Second, we describe how we conceptualised the offence process and draw from the established evidence base. Lastly, we detail the rationale for adopting the present analytical strategy.

The RAF draws on Situational Action Theory (SAT) and opportunity theories to hypothesise multilevel mechanisms that underlie causal processes in pathways to extremist violence. ${ }^{16}$ A detailed presentation of the RAF is beyond the scope of this paper (see ${ }^{17}$ for a detailed discussion). In brief, the framework, which synthesises causal models of terrorism and radicalisation previously developed by Bouhana and Wikström ${ }^{18}$ was developed to articulate relations between causal factors and processes at multiple levels of analysis, across each phase of an extremist event.

The RAF conceives of the offence process as the outcome of the interaction between individuals with action-relevant propensities and terrorism-supportive criminogenic settings, whose features support these individuals' perception of their own capability to offend, leading to the emergence of situations that trigger and sustain actors' motivation to commit an act of terrorism. As a general, interactionist framework, the RAF articulates key mechanisms and processes, as opposed to discrete indicators, which are theorised to be context-dependent, and therefore unstable ground for risk assessment ${ }^{19}$. While the RAF has so far been used to guide research on lone-actor terrorists, it is a general framework for the analysis of offending risk. It is, therefore, an appropriate framework for a comparative study of both mass murderers and lone-actor terrorists.

In the present study, we demonstrate a dynamic reconceptualisation of these types of offenders. To do so, it is necessary to conceptualise the offending process into distinct components and operationalise these with observable indicators. Decisions about how 
existing indicators mapped onto components of the offence process were guided by the RAF. This has been done previously ${ }^{20}$ and although by no means perfect, has the advantage of being theoretically-guided, rather than $a d$ hoc. Based on prior research, we theorise LAGFV risk as emerging from the interaction between propensity, situation, preparatory, network and leakage indicators.

\section{Propensity}

Propensity is understood as the outcome of the developmental interaction between an individual's differential susceptibility and their exposure to violence-supporting settings. ${ }^{21}$ Factors related to the emergence of a violent propensity in LAGFV have been researched extensively. Research on mass murder has examined sociodemographics, ${ }^{22}$ mental illness, ${ }^{23}$ social isolation, ${ }^{24}$ chronic strain, ${ }^{25}$ and previous criminality ${ }^{26}$ as factors relating to relative risk of engaging in mass violence. There is also significant research into these factors in loneactor terrorism. ${ }^{27}$ However, no stable profile of these characteristics exists. Hence, their predictive utility is limited. However, interactions among these factors may allude to the emergence of a propensity for LAGFV, and therefore this is important to consider.

\section{Situation}

Situation relates to immediate behavioural influences, such as stressors and negative life experiences, in the build-up to an attack. A transitional period of acute stressors is often described in pathways to LAGFV. For example, Silver et al. ${ }^{28}$ explored the role of strain, both chronic and acute, in trajectories to mass murder. Similarly, Lankford ${ }^{29}$ examined $^{-}$ situational stressors in suicide terrorists and rampage shooters. The role of situational stressors has been examined in lone 'wolf' violent offenders, ${ }^{30}$ in a comparison of German jihadi and school attackers, ${ }^{31}$ adolescent mass murderers, ${ }^{32}$ mass murderers at school, ${ }^{33} \mathrm{US}$ 
mass murderers, ${ }^{34}$ and in the context of a 'triggering event' in mass murderer trajectories. ${ }^{35}$ These indicators can signal the emergence and maintenance of a motivation to pursue LAGFV, and so are important to consider here. ${ }^{36}$

\section{Preparatory}

Preparatory indicators relate to how offenders prepare for an attack. In contrast to single homicide events, terrorist and mass murder events appear more purposive in that they typically involve a period of planning. ${ }^{37}$ The preparatory behaviours of lone-actor terrorists have been studied extensively; ${ }^{38}$ so too of mass murderers. ${ }^{39}$ Previous comparisons of mass murderers and lone-actor terrorists report significant differences in the way these offenders prepare for an attack. ${ }^{40}$ Hence these factors are pertinent to consider.

\section{Leakage}

'Leakage' is the extent to which offenders communicate their intent and/or capability to third parties prior to the offence. Research on both mass murderers and lone-actor terrorists demonstrates that these offenders do so either by directly communicating a threat or by exhibiting warning behaviours. ${ }^{41}$ These indicators are particularly important to the threat assessment of LAGFV, as they provide an opportunity for detection and intervention.

\section{Network}

Lastly, we consider network connectivity. The extent to which lone-actor terrorists are 'lone' has been debated widely. ${ }^{42}$ Much of this research concludes that these offenders are not as 'lone' as the moniker implies. In fact, recent research calls for an "end to the lone wolf" typology. ${ }^{43}$ Some may act in complete isolation however this does not reflect the majority of cases. Malthaner \& Lindeklide ${ }^{44}$ go further in analysing lone-actor pathways to 
radicalisation from a relational perspective. They argue not only do lone-actor terrorists vary in the degree of isolation within which they operate, but also with respect to how they interact with others (i.e. militants, radical milieus, or virtual communities) along pathways to radicalisation. This is of relevance to disaggregating LAGFV offenders as research that examines the differences between ideologically and non-ideologically motivated attacks has found that connections to others, or the lack thereof, are a significant difference between these types of offenders. ${ }^{45}$ Next we detail the analytical strategy adopted.

Previous research on crime uses analytical strategies such as cluster analysis, or latent class analysis, to detect latent sub-groups in offending populations. Populations are disaggregated upon a number of variables of interest in order to identify un-measured class membership. The different classes are often conceptualised as types in a typology. For example, this analytical strategy developed typologies of a range of offenders, including nonserial sexual killers, ${ }^{46}$ sex offenders who target marginalised victims, ${ }^{47}$ extrafamilial sexual aggressors against women, ${ }^{48}$ intrafamilial child sex offenders, ${ }^{49}$ extrafamilial sexual aggressors against adolescents, ${ }^{50}$ and marital rapists. ${ }^{51}$ Similarly, latent class analysis has been used to develop offender profiles of burglars, ${ }^{52}$ sexual burglary, ${ }^{53}$ participants in drug treatment court, ${ }^{54}$ and dating violence. ${ }^{55}$ More recently, Clemmow, Bouhana \& Gill ${ }^{56}$ developed a typology of person-exposure patterns (PEPs) in cases of lone-actor terrorism. Hence there is reason to believe this may be an effective strategy to disaggregate LAGFV. Hence we use cluster analysis to examine the extent to which an aggregate dataset of solo mass murders and lone-actor terrorists, can (or cannot) be disaggregated.

\section{Method}

\section{Data}


This study makes use of two pre-existing datasets of lone-actor terrorists ${ }^{58}$ and mass murderers ${ }^{59}$ Lone-actor terrorists were identified if cases met the following criteria: offenders carried out or planned to carry out an ideologically motivated attack, alone. Within the sample, offenders can operate with or without command-and-control links. Some operated autonomously and independently of a group, however, some may have radicalised towards violence within a wider group. Those with command and control links may have been trained and equipped by a group - which may also choose their targets - but attempted to carry out their attacks autonomously. Subjects were either convicted for their offences or died in the commission of an attack. Offenses occurred between 1990 and 2016. To ensure a consistent context, only US lone-actor terrorists were included in the present analysis $(n=$ $68)$.

Mass murderers were identified if cases satisfied the following criteria: offenders killed at least four victims (excluding the offender) at one (or multiple but geographically close) locations, over a relatively short period of time. For the purposes of comparison, only mass murderers who committed an attack alone were included in the sample, $(n=115)$. Acts identified as state-sponsored, solely domestic, or gang and/or organised crime-related, were excluded. Offenses occurred between 1990 and 2014. The final dataset consisted of 183 offenders.

The data were compiled from open sources, including sworn affidavits, court reports, and news reports, obtained via LexisNexis searches. Additional sources, such as biographies, were used where available and relevant. First, three independent coders coded the objective absence or presence of an indicator. Second, coders engaged in a two-stage reconciliatory process. First, coder A reconciled observations with coder B. Where differences occured, the original source documentation was consulted. Second, coders AB reconciled with coder C. Again, disparities were resolved by one of the principal researchers, who revisited the 
original sources and factored in the reliability of the documents. This decision-making was guided by a 'continuum of reliability', whereby each source was plotted along a scale from 'most reliable' to 'least reliable'. This has been done previously in studies utilising opensource data ${ }^{60}$ as well as when constructing open source databases such as the US Extremist Crime Database (ECDB) ${ }^{61}$ Components of the offense process were operationalised with existing indicators (see Appendix A for the full codebook).

\section{Procedure}

\section{Analytical strategy}

We used cluster analysis to identify groups of related cases within each of the components of the attack process. The two-step cluster analysis function in Statistical Program for Social Sciences (SPSS) version 25 was used. Clusters were identified within all five components: propensity, situation, preparatory, network and leakage. One way to measure the homogeneity of the cluster solution is the silhouette measure of cohesion and separation. This measure articulates how cohesive the clusters are within themselves and how separate they are from one another. Potential values range from -1 to +1 . In a perfect solution, the within-cluster distances are small and the between- cluster distances are large. This would be represented by a value close to 1 . If the inverse is true, a value close to -1 would be expected. To guide interpretation, the values are summarised as poor, fair or good in the model summary generated by SPSS. A value summarised as fair, for example, would indicate a fair degree of separation (and cohesion (the clusters are fairly homogenous within themselves). This can further be seen by examining the relative frequencies in the results tables. Post-hoc z-tests compared the column proportions to determine the extent to which the clusters classified offenders previously labelled as lone-actor terrorists or mass murderers. 
Bi-variate analysis established associations among the theorised components and a model of LAGFV was proposed.

\section{Results}

The clusters identified at each component were labelled by interpreting the patterns of indicators observed. In the following tables, indicators appear in order of their salience and importance to the overall cluster solution. Highlighted are the most salient features of each cluster. It is important to note that the clusters are not presented as 'types of people', but rather as patterns of indicators to be interpreted as styles of interaction. ${ }^{62}$

\section{Propensity}

We identified three clusters, (see Table 1). Given the variables that made up these clusters, they were labelled, criminal, stable, and unstable. The silhouette measure of cohesion was .2, which is fair.

\section{(TABLE 1)}

The criminal cluster typifies criminality. All (100\%) of these offenders had previous criminal convictions and $71.9 \%$ were previously imprisoned. The nature of this criminality is likely more severe, given the rate of imprisonment. These offenders were less educated than their counterparts where only $12.5 \%$ had some university education, and just $1.6 \%$ demonstrated exceptional academic achievements. Approximately $20 \%$ were arrested as juveniles and $53.1 \%$ experienced chronic stress. This resonates with previous findings about multiple homicides, whereby $30 \%$ of offenders were classified as habitual criminals before their final event. ${ }^{63}$

The stable cluster are not 'stable', in that these offenders did go on to commit grievance-fuelled violence. However, the presenting patterns of indicators is unremarkable relative to the unstable and criminal clusters. This cluster demonstrated lower frequencies of 
propensity factors typically associated with the emergence of LAGFV. For instance, $25.5 \%$ of had previous criminal convictions. The criminality here is most likely petty, as only $7.3 \%$ of these offenders were previously imprisoned. Fewer of these offenders were unemployed $(10.9 \%)$ or experienced chronic stress $(0 \%)$, and $32.7 \%$ had a diagnosed mental illness. Of note: $29.1 \%$ had previous military experience.

Lastly, the unstable cluster was characterised by high frequencies of diagnosed mental illness (67.2\%) and chronic stress (92.2\%). Only 9.4\% had previous criminal convictions and just $1.6 \%$ had been imprisoned. They were more often socially isolated (51.6\%) and interestingly, $25.0 \%$ had been rejected from the military. The pervasive pattern of instability, including mental illness, may offer an insight into why a quarter of these offender were rejected from the military.

We examined the extent to which cluster membership was associated with actor type. The relationship was significant, $X^{2}(2, N=183)=24.77, p<.000, V=.37$. Post-hoc z-tests compared the column proportions, (see Figure 1). A significantly higher proportion of mass murderers were classified as stable (44.4\%) compared to lone-actor terrorists (19.1\%), p $<.000$. There was no significant difference between the proportion of mass murderers (36.5\%) and lone-actor terrorists (32.4\%) classified as criminal. A significantly higher proportion of lone-actor terrorists $(25 \%)$ than mass murderers $(6 \%)$, were classified as unstable, $\mathrm{p}<.001$.

(FIGURE 1)

\section{Situation}

We identified three clusters, labelled low stress, high stress (social) and high stress (interpersonal) (see Table 2). The silhouette measure of cohesion was .3, which is fair.

(TABLE 2) 
The clusters differentiate by gradations of situational stressors, as well as between different types of stress, here classified as social or interpersonal. Stress refers to a transitional period of acute stressors in the build-up to an attack. The low stress cluster demonstrated lower frequencies of these indicators where $0 \%$ were ignored by someone important to them, $0 \%$ had someone important to them demonstrate they did not care, $10 \%$ experienced prejudice and/or injustice, and 9.6\% experienced being degraded and/or disrespected.

In contrast, the high stress clusters demonstrate much higher frequencies of these behaviours. First, the high stress (social) cluster demonstrated higher frequencies of injustice and/or prejudice $(68.7 \%)$, being degraded $(65.7 \%)$, and being disrespected $(65.7 \%)$. The nature of these experiences relates more broadly to wider social grievances. However, the high stress (interpersonal) cluster demonstrates a different pattern of situational stressors. These offenders experienced being ignored (84.8\%), felt not cared for $(81.8 \%)$, and had problematic personal relationships (93.9\%). The nature of these experiences relates more to problematic interpersonal relationships and reflects findings about the nature of grievances in mass murder. ${ }^{64}$

We examined the extent to which cluster membership was associated with actor type. The relationship was significant, $X^{2}(3, N=183)=13.24, p<.01, V=.27$. Post-hoc z-tests compared the column proportions, (see Figure 2). A significantly higher proportion of loneactor terrorists were classified as low stress (59\%) compared to mass murderers (37\%), p $<.005$. There was no significant difference between the proportion of mass murderers (37\%) and lone-actor terrorists (35\%) classified as high stress (social). A significantly higher proportion of mass murderers $(25 \%)$ than lone-actor terrorists $(6 \%), \mathrm{p}<.001$ were classified as high stress (interpersonal). 


\section{Preparatory}

We identified six clusters, labelled novel aggression, predatory, clandestine, preparatory, fixated and equipped (see Table 3 ). The silhouette measure of cohesion was .2, which is fair.

\section{(TABLE 3)}

The novel aggression cluster was characterised by high frequencies of offenders committing acts of violence, unrelated to their attack, in the build-up to the event. This novel aggression occurs as offenders prepare psychologically and test their resolve to commit violence in the build-up to an attack. Offenders demonstrated low frequencies of practical preparatory behaviours, such as conducting dry-runs $(0 \%)$, altering their appearance $(0 \%)$, travelling to prepare for an attack (0\%), and hands-on training (0\%). Notably, $69.4 \%$ of this cluster had a history with the event location, which may mitigate the need for preparatory behaviours.

The predatory cluster were classified by a pattern of novel aggression (97.1\%) alongside practical preparatory behaviours. Here, $23.5 \%$ of offenders engaged in dry-runs, $61.8 \%$ changed their address in the build-up to an attack, $61.8 \%$ stockpiled weapons, and $14.7 \%$ sought legitimisation for their actions. This style of interaction is comparable to the predatory offender in typologies of mass murderers. ${ }^{65}$

The clandestine cluster demonstrated higher frequencies of preparatory behaviours related to maintaining operational security. For instance, these offenders altered their appearance (15.4\%), changed address (92.3\%), and cleared out their bank account $(23.1 \%)$. Preparatory behaviours that may increase the likelihood of detection such as travelling to prepare for an attack (2.8\%), engaging in dry-runs (11.5\%), novel aggression (3.8\%) and stockpiling weapons $(0 \%)$, occurred at lower frequencies here. 
The preparatory cluster demonstrated high frequencies of preparatory behaviours. This cluster is consistent with research on LAGFV which repeatedly identifies patterns of preparatory behaviours in trajectories to mass violence. ${ }^{66}$

The fixated cluster is characterised most saliently by an obsession with an event and/or phenomenon in the build-up to the event, where offenders had a history with the event location. In this instance, the event location is likely significant to their grievance. This is comparable to research on paranoid thinking in mass shooters. Offenders who have been rejected from a target group may become obsessed with the status of that group. The offender is framed as an 'outsider' and becomes obsessed with their perceived mistreatment. ${ }^{67}$ Similarly, Knoll and Meloy ${ }^{68}$ found evidence for a violent-paranoid spectrum in mass murderers via the psycholinguistic analysis of communications left behind by a sample of these offenders. Offenders described feelings of social persecution and thoughts of revenge against a target group.

Lastly, the equipped cluster demonstrate low frequencies of preparatory behaviours. However, $100 \%$ of this cluster had access to a stockpile of weapons. Research on mass murderers and lone-actor terrorists consistently reports a planning stage. Indeed, Meloy ${ }^{69}$ dispels the common misconception that mass murderers are deranged offenders who 'just snap'. Mass murderers are consistently found to be methodical in planning and preparation. ${ }^{70}$ This is true also of lone-actor terrorists who consistently demonstrate antecedent planning behaviours. ${ }^{71}$ However, this cluster may classify a group that are more impulsive and act without extensive planning due to their access to weapons.

We examined the extent to which cluster membership was associated with actor type. The relationship was significant, $X^{2}(5, N=183)=39.23, p<.01, V=.46$. Post-hoc z-tests compared the column proportions, see Figure 3. A significantly higher proportion of mass murderers $(25 \%)$ were classified as fixated compared to lone-actor terrorists $(3 \%), \mathrm{p}<.000$. A 
significantly higher proportion of mass murderers (27\%) were classified as novel aggression compared to lone-actor terrorists $(7 \%), \mathrm{p}<.001$. There were no significant differences between the proportion of mass murderers and lone-actor terrorists classified as equipped (13\% versus $12 \%$ ) or clandestine (12\% versus $18 \%)$. A significantly higher proportion of lone-actor terrorists $(28 \%)$ than mass murderers $(13 \%)$, were classified as predatory $\mathrm{p}<.05$. Lastly, a significantly higher proportion of lone-actor terrorists (32\%) were classified as preparatory than mass murderers $(10 \%), \mathrm{p}<.000$.

(FIGURE 3)

\section{Leakage}

We identified two clusters, labelled high leakage and low leakage (Table 4). The silhouette measure of cohesion was .5 , which is good.

(TABLE 4)

The high leakage cluster demonstrate higher frequencies of leakage behaviours than the low leakage cluster. Leakage of intent is key to the threat assessment of different types of LAGFV. The low leakage cluster identifies a subgroup of offenders who do not leak their intent, in contrast to much existing research. This is comparable to the configuration of the solitary PEP, identified by Clemmow et al. ${ }^{72}$ Therefore, it may be necessary to consider a trajectory absent of leakage indicators as still posing a credible threat.

We examined the extent to which cluster membership was associated with actor type. The relationship was significant, $X^{2}(1, N=183)=11.26, p<.01$. Post-hoc z-tests compared the column proportions, as can be seen in Figure 3. A significantly higher proportion of loneactor terrorists were classified as high leakage (82.0\%) compared to mass murderers $(58.0 \%)$, $\mathrm{p}<.001$. A significantly lower proportion of lone-actor terrorists $(18.0 \%)$ were classified as low leakage compared to mass murderers $(42.0 \%), \mathrm{p}<.001$. 


\section{Network}

We identified three clusters, labelled lone, associated and connected (Table 5). The silhouette measure of cohesion was .5 , which is good.

\section{(TABLE 5)}

The cluster solution disaggregates network connections by their degree of 'loneness'. In the lone cluster, $0 \%$ of the 80 offenders demonstrate any network connections. In contrast, the connected cluster demonstrates higher frequencies of these behaviours. We examined the extent to which cluster membership was associated with actor type. The relationship was significant, $X^{2}(2, N=183)=46.48, V=.50, p<.000$. Post-hoc z-tests compared the column proportions, as can be seen in Figure 5. A significantly lower proportions of lone-actor terrorists were classified as lone $(16 \%)$ compared to mass murderers $(60 \%), \mathrm{p}<.000$. There was no significant difference between the proportion of mass murderers (33\%) and lone-actor terrorists (43\%) classified as associated. A significantly lower proportion of mass murderers $(7 \%)$ than lone-actor terrorists $(43 \%), \mathrm{p}<.000$ were classified as connected.

\section{(FIGURE 5)}

\section{Modelling interactions in LAGFV}

Associations between the offending profiles were examined with chi square tests. The propensity offending profiles were significantly associated to the situation offending profiles $\left(X^{2}(4, N=183)=11.00, V=.17, p<.05\right)$. The situation offending profiles were associated with the leakage offending profiles, $\left(X^{2}(2, N=183)=24.77, V=.37, p<.000\right)$. Leakage profiles were associated with the network offending profiles $\left(X^{2}(2, N=183) 13.77, V=.27\right.$, $p<.00)$ and preparatory offending profiles $\left(X^{2}(5, N=183)=14.77, V=.28, p<.05\right)$. Finally, network profiles were associated to preparatory profiles $\left(X^{2}(10, N=183)=34.06, V=.31, p\right.$ 
$<.000)$. All other tests were not significant. Based on these associations, Figure 6 proposes an interactional model of LAGFV.

(FIGURE 6)

\section{Discussion}

In this section, first, we discuss the proposed model and the interacting components. Second, we acknowledge the limitations of the study. Third, we consider the wider implications of our findings for the threat assessment and management of these offenders.

\section{Modelling LAGFV}

The model articulates the relations between the theorised components of the LAGFV offending process. First, the propensity component was found to be significantly associated to the situation component. The clusters identified at the propensity component operationalise differential susceptibilities to LAGFV. For example, an offender classified as unstable, exhibiting diagnosed mental illness, chronic stress, and who is socially isolated, likely has a predisposed vulnerability to engaging in this type of violence. Similarly, a career criminal, classified as criminal here, likely has a different type of predisposition to engage in demonstrative violence. Interestingly the stable cluster highlights a profile of offenders who do not exhibit a pattern of indicators most often associated with engaging in this type of violence.

These findings suggest how different patterns of propensity factors may influence (or be related to) the unfolding of differential patterns of indicators at further components. To note, the reported associations are not hypothesised as linear relationships, as it is likely that these interactions are more complex and multidirectional. For instance, high stress (interpersonal) offenders may be unstable because pervasive instability at the individuallevel leads to problematic interpersonal relationships. It may also be true that problematic 
interpersonal relationships negatively impact upon factors such as mental illness and social isolation. Hence, the results demonstrate the importance of considering such factors dynamically.

Considering leakage, Meloy and O’Toole (pg. 525) ${ }^{73}$ state that “ $[\mathrm{t}]$ he relationship between leakage and other warning behaviours may be critical for prediction, but this is an empirical question yet to be answered." The present findings go some way to addressing this by demonstrating the dynamicity of leakage as a process, rather than as a static indicator. The leakage component was significantly associated to the situation component. Hence, the likelihood of an offender leaking their intent may be related to the nature of their experiences in the build-up to an attack.

The leakage component was also found to be significantly associated to the preparatory component. Again, these findings reiterate the importance of considering an offender's context, or situation. Leakage was also related to network connectivity. Hence, whether an offender leaks their intent may be related to experiences of (or a lack thereof) acute stressors in the build-up to an attack, the way they prepare for an attack, and their connectivity to others.

Therefore, relying on static profiles of these indicators as measures of relative risk may be problematic. These results reiterate findings that demonstrate the multifinality and instability of risk indicators in the threat assessment of such offenders. ${ }^{74}$ Findings such as these provide further support for a different approach to the risk analysis of this type of offender. Researchers of school shootings have advocated for a move away from researching individual risk factors, or isolated influences such as gun laws, and towards a more holistic approach that looks at the entirety of what they term 'violence-supporting settings. ${ }^{75}$ Whilst the present study only had scope to operationalise factors at the individual and situational 
levels, these findings demonstrate the potential for adopting such an approach and reevaluating the risk analysis of these types of offenders.

Lastly, the network component was significantly associated with the preparatory component. This association may account somewhat for the perceived differences between the capability and preparatory behaviours of ideologically and unideologically motivated lone-actors. Research comparing the preparatory behaviours and capability of these types of offenders repeatedly finds significant differences, and therefore often asks, does ideology matter ${ }^{76}$ However, the differences between ideologically and unideologically motivated attacks are not necessarily caused by an extremist ideology. The causes of these differences may instead be rooted in the underlying processes that direct a person's exposure to different violence-supportive settings. ${ }^{77}$

Conceptual models of radicalisation often refer to a 'seeking' phase, whereby a cognitive opening as the result of a transitional period of acute crisis and situational interactions, motivates an offender towards a narrative that they perceive can address their needs and/or grievance. ${ }^{78}$ For example, McCauley and Moskalenko ${ }^{79}$ describe the process of unfreezing, where a transitional period can make an individual more open to influence. Similarly, research on mass murderers often describes a period of affective turmoil that precipitates violence. ${ }^{80}$ However, a person's context is likely to influence the type of violence-supporting settings they encounter and the types of narratives they are exposed to, through selection processes. For example, mass murderers are often white, middle-class men. Levin and Madfis ${ }^{81}$ describe how mass murder is the outcome of a rational choice in light of a discord between an offender's expectations for their lives, (i.e. wealth, academic/professional success) and the reality they are faced with after prolonged periods of chronic strain and a transitional period of acute strain. Individual characteristics, such as ethnicity, and the availability of violence-supporting settings, may determine the nature of the 
narratives these offenders are likely to identify with, i.e. the mass murderer narrative that invokes fame, notoriety, revenge, or some other resolve for their grievance. In contrast, a second-generation Muslim immigrant living in an area known to contain radicalising settings is more likely to be exposed to an Islamist-inspired narrative. The subsequent differences observed between the effectiveness and capabilities of these two offenders, may be rooted in how identifying with these narratives facilitates wider network connections.

First, a collective ideology, central to the terrorist narrative may foster more opportunities for developing relationships with other extremists. Whereas in mass murder, the lack of a group ideology, by definition, may limit the extent to which these offenders are exposed to opportunities to form wider connections. Second, conceptualising network connectivity as a component operationalised some of the factors hypothesised to sustain offender perception of capability (i.e. support received from others) and therefore their motivation to act. Hence, offenders who establish connections to others, here predominantly ideologically-motivated offenders, are likely to prepare for an act of mass violence differently, due to heightened, real or perceived, capability. In other words, ideology, per se, does not matter. Rather, it is a complex interaction of multiple, multilevel mechanisms, that relate to an offender's capability and motivation to commit an act of mass violence, that matters. ${ }^{82}$

\section{Limitations}

The present study is limited in that the data were not collected for the purpose of the present analysis and hence was dependent upon the available indicators. Much of the data in this space is characterised by missing data and biases with regards to the nature of what is missing. ${ }^{83}$ Given the nature of the data, there is likely to be underreporting of certain types of indicators, whereby traditional news reporting favours indicators such as mental illness or 
substance abuse. This is often a limitation of open source data. However, the present research draws inferences based on patterns of multiple indicators, and whilst certainly not exempt from the availability bias, may be somewhat more resilient to its effects. By operationalising observable indictors that are often available to analysts, whilst not a perfect solution, we would contend is acceptable.

More generally, the data were open source. Relying on secondary-source data collection methodologies has been criticised for resulting in data that are unreliable, subject to bias, and incomplete. ${ }^{84}$ However, conducting research in this space necessitates researchers to make certain choices, whilst acknowledging their limitations. Open source data has been the source of a range of important findings. ${ }^{85}$ Robust data collection methodologies and provisions to ensure inter coder reliability can mediate many of these concerns, as in the present study. In fact, Gill et al. ${ }^{86}$ demonstrated the present data collection methodology elicited comparable results when using closed sources.

Finally, it is important to consider the treatment of missing data. When relying on open-source reporting it is difficult to decipher between missing data, and data that should be coded as 'no' or 'not present'. The authors of these sources are unlikely to report the absence of potentially infinite indicators that may be of interest to researchers. ${ }^{87}$ Hence, each variable in the analysis is treated dichotomously, where the response is either a 'yes' or not enough information to suggest a 'yes' and, therefore, a 'no'. Previous research on attempted assassinations of public figures, fatal school shootings, and targeted violence affecting higher education institutions and terrorism, have employed similar strategies. ${ }^{88}$

\section{Implications for threat assessment}

Research widely acknowledges it is near impossible to accurately predict LAGFV based on static risk factors. This is largely because of low base rates, and a lack of sensitivity 
and specificity that results in large numbers of false positives. ${ }^{89}$ A number of terrorism risk assessment tools exist in current practice. For example, the ERG22+ utilised by the UK National Offender Management System, ${ }^{90}$ and the Violent Extremism Risk Assessment (VERA-2) utilised in prisons and by probation services ${ }^{91}$. Similarly, there are a number of mass murder risk assessment tools such as the Dallas Threat of Violence Risk Assessment (DTVRA), implemented in US schools. ${ }^{92}$ Beyond the problems of specificity and sensitivity, a static, indicator-orientated approach to risk assessment may be problematic given the present findings, and research that has demonstrated the multifinality of these indicators. ${ }^{93}$ Rather, a threat assessment and structured professional judgement (SPJ) approach to mitigating this type of violence has been proposed. ${ }^{94}$

Threat assessment in the US has predominantly been undertaken by separate agencies and employs a range of frameworks as guidance. For example, in cases of adolescent school shooters, the Structured Assessment of Violence Risk in Youth (SAVRY) is a SPJ tool that promotes dynamic, clinical judgements of risk in schools. ${ }^{95}$ Similarly, the Workplace Assessment of Violence Risk (WAVR-21) is a SPJ tool for assessing the risk of targeted violence in the workplace. ${ }^{96}$ In higher education settings, STEM summarises four domains of concerning behaviours as guidance for local Threat Assessment Teams (TAMs) ${ }^{97}$

Given the evidence for reconceptualising these types of homicide generally, our findings suggest an overarching framework for guiding the threat assessment of LAGFV may be feasible. For instance, Meloy and $\mathrm{O}^{\prime}$ Toole $^{98}$ summarise eight warning behaviours as a SPJ framework for the threat assessment of targeted violence. This typology of warning behaviours appears in practice as part of the Terrorist Radicalisation Assessment Protocol (TRAP-18), ${ }^{99}$ alongside 10 specific background characteristics. The present study goes further by articulating patterns of indicators of interest to practitioners, and hence may be useful additional guidance to inform a general threat assessment framework. 
Such an approach relies on gathering relevant intelligence and effective decisionmaking. Post 9/11, counterterrorism policing has evolved towards an Intelligence-led Policing (ILP) model. ${ }^{100}$ Given the extensive planning and preparatory behaviours of LAGFV offenders, the threat they pose is theoretically detectable. In fact, Capellan and Lewandowski ${ }^{101}$ find encouraging evidence in support of a Secret Service ILP tool in a retrospective analysis of public mass shootings. However, for an ILP approach to be effective, multi-agency intelligence-sharing is a key. ${ }^{102}$ Relevant intel is likely to originate from a multitude of sources including mental health practitioners, police records, and the community. Hence, it is important to consider policy aimed at enabling efficient networks of intelligence sharing.

In counterterrorism, intelligence hubs such as the fusion centres in the US, the Integrated Security Units (ISUs) and the Integrated Threat Assessment Centre (ITAC) in Canada, as well as the safeguarding hubs that operate as part of the UK's PREVENT strategy, are central to such endeavours. ${ }^{103}$ Carter et al. ${ }^{104}$ conducted a survey of fusion centres and state, local and tribal agencies (SLT) and found that respondents signalled there was still a long way to go to building an intelligence capacity. In fact, of the SLT's surveyed, just $18.6 \%$ reported that their agency had adopted ILP. Progress has been made in the subsequent years, however there is still arguably room for improvement.

Intelligence is key to mitigating the risks of these sorts of offenders and hence the present findings lend further support for developing a more robust intelligence-capability. A key function of these centres and their equivalents is to facilitate information sharing. Chermak et al., (p.g. 228) ${ }^{105}$ state that "organisations and individuals must know how to identify relevant threat information, collect it without violating civil liberties, know who the information should be shared with, and must be willing to share it." The present findings specifically, may be operationalised as a tool for identifying relevant threat information, and 
more generally, may provide further evidence to continue to advocate for effective multiagency information sharing. Carter et al. ${ }^{106}$ outline how this should be achieved whilst safeguarding privacy.

The establishment of the DHS office for the Targeted Violence and Terrorism Prevention signals a move towards implementing existing intelligence-gathering capabilities to better target LAGFV in general. Our findings could provide empirically based guidance to inform a) what sort of intelligence to collect, and b) aid decision-making in the allocation of limited resources. Since it was established, DHS released the office's strategic framework for countering terrorism and targeted violence. In particular they outline an enhanced intelligence-capability. DHS states (p.6) ${ }^{107}$ "Strong intelligence capabilities allow the Department and its partners to understand the nature of the threat facing the Homeland, allowing DHS to prevent and mitigate threats...”. The findings of the present study may provide a more nuanced understanding of the nature of the threat of LAGFV. 
Notes

1. Capellan, Joel A. "Lone wolf terrorist or deranged shooter? A study of ideological active shooter events in the United States, 1970-2014." Studies in Conflict \& Terrorism 38.6 (2015): 395-413.; Capellan, Joel Alfredo, and Alexei Anisin. "A distinction without a difference? Examining the causal pathways behind ideologically motivated mass public shootings." Homicide Studies 22.3 (2018): 235-255; John Horgan, et al. "Across the universe? A comparative analysis of violent radicalization across three offender types with implications for criminal justice training and education." (2016).

2. Borum, Randy, Robert Fein, and Bryan Vossekuil. "A dimensional approach to analyzing lone offender terrorism." Aggression and Violent Behavior 17.5 (2012): 389-396.

3. Leiter, M., \& Sheetan, M. (2018, April 5, 2018). Treat mass shootings the way we treated terrorism. The Washington Post. Retrieved from https://www.washingtonpost.com/opinions/treat-mass-shootings-the-way-we-treatedterrorism/2018/04/05/e4235e14-375f-11e8-acd5$\underline{35 e a c 230 e 514 \text { story.html?utm_term=.ff272b2ea0c8 }}$

4. Department of Homeland Security. (2019) Retrieved on 29th May, 2019. Acting Secretary McAleenan Announces Establishment of DHS Office for Targeted Violence and Terrorism Prevention.

5. Lankford, Adam. "A comparative analysis of suicide terrorists and rampage, workplace, and school shooters in the United States from 1990 to 2010." Homicide studies 17.3 (2013): 255-274.

6. Lankford, Adam. "Detecting mental health problems and suicidal motives among terrorists and mass shooters." Criminal behaviour and mental health 26.5 (2016): 315-321; Lankford, Adam. "Identifying potential mass shooters and suicide terrorists 
with warning signs of suicide, perceived victimization, and desires for attention or fame." Journal of personality assessment 100.5 (2018): 471-482; Lankford, Adam, and Nayab Hakim. "From Columbine to Palestine: A comparative analysis of rampage shooters in the United States and volunteer suicide bombers in the Middle East." Aggression and violent behavior 16.2 (2011): 98-107.

7. Capellan and Ansisin. (2018)

8. Lyons, H. Alex, and Helen J. Harbinson. "A comparison of political and non-political murderers in Northern Ireland, 1974-84." Medicine, Science and the Law 26.3 (1986): 193-198.

9. Böckler, Nils, et al. "Same but Different? Developmental Pathways to Demonstrative Targeted Attacks-Qualitative Case Analyses of Adolescent and Young Adult Perpetrators of Targeted School Attacks and Jihadi Terrorist Attacks in Germany." International journal of developmental sciencePreprint (2018): 1-20.

10. Gruenewald, Jeff. "A comparative examination of homicides perpetrated by far-right extremists." Homicide studies 15.2 (2011): 177-203; Gruenewald, Jeff, and William Alex Pridemore. "A comparison of ideologically-motivated homicides from the new extremist crime database and homicides from the supplementary homicide reports using multiple imputation by chained equations to handle missing values." Journal of Quantitative Criminology 28.1 (2012): 141-162.

11. Liem, Marieke, et al. "European lone actor terrorists versus "common" homicide offenders: An empirical analysis." Homicide studies 22.1 (2018): 45-69.

12. Capellan (2015); Horgan, Gill et al. (2016); Silver, J., Horgan, J., \& Gill, P. (2019). Shared Struggles? Cumulative Strain Theory and Public Mass Murderers From 1990 to 2014. Homicide Studies, 23(1), 64-84. 
13. Thompson, Carleen M., Anna L. Stewart, and Susan M. Dennison. "Using Dynamic Contextual Factors to Better Understand the Etiology and Escalation of Stalking Violence." Criminal Justice and Behavior (2019): 0093854819878234.

14. Ibid, 2019

15. Corner, Emily, Noémie Bouhana, and Paul Gill. "The multifinality of vulnerability indicators in lone-actor terrorism." Psychology, Crime \& Law 25.2 (2019): 111-132.

16. Bouhana, N., Thornton, A., Corner, E., Malthaner, S., Lindekilde, L., Schuurman, B., \& Perry, G., (2016). D3.1 Risk Analysis Framework: Public Version. FP7 PRIME project, 1-107. Accessed from: http://www.fp7prime.eu/deliverables/PRIME_D3.1_Risk_Analysis_Framework_Public.pdf

17. Bouhana et al. (2016); Noémie Bouhana, (2019, July 31). The moral ecology of extremism: a systemic perspective. Retrieved from https://assets.publishing.service.gov.uk/government/uploads/system/uploads/attachme $\underline{\text { nt_data/file/834354/Bouhana-The-moral-ecology-of-extremism.pdf }}$

18. Bouhana, Noemi, and P-OW Wikstrom. "Theorising terrorism: A scoping study." Contemporary Readings in Law and Social Justice 2.2 (2010): 9-79.; Bouhana, Noemie, and P-OW Wikstrom. "Al Qai'da-Influenced Radicalisation: A Rapid Evidence Assessment Guided by Situational Action Theory." (2011); Wikström \& Bouhana. (2016).

19. Bouhana et al., 2016; Clemmow, Caitlin, Noémie Bouhana, and Paul Gill. "Analyzing person-exposure patterns in lone-actor terrorism: Implications for threat assessment and intelligence gathering." Criminology \& Public Policy (2019); Corner, Bouhana, \& Gill, 2019.

20. Corner et al., 2019

21. Wikström and Bouhana, 2016 
22. Auxemery, Yann. "The mass murderer history: Modern classifications, sociodemographic and psychopathological characteristics, suicidal dimensions, and media contagion of mass murders." Comprehensive psychiatry 56 (2015): 149-154; Capellan, Joel A., et al. "Disaggregating mass public shootings: a comparative analysis of disgruntled employee, school, ideologically motivated, and rampage shooters." Journal of forensic sciences 64.3 (2019): 814-823; Gill, Paul, et al. "Shooting Alone: The pre-attack experiences and behaviors of US solo mass murderers." Journal of forensic sciences 62.3 (2017): 710-714; Taylor, Melanie A. "A comprehensive study of mass murder precipitants and motivations of offenders." International journal of offender therapy and comparative criminology 62.2 (2018): 427-449.

23. Ferguson, Christopher J., Mark Coulson, and Jane Barnett. "Psychological profiles of school shooters: Positive directions and one big wrong turn." Journal of Police Crisis Negotiations11.2 (2011): 141-158; Flannery, Daniel J., William Modzeleski, and Jeff M. Kretschmar. "Violence and school shootings." Current psychiatry reports 15.1 (2013): 331; Fox, Jaclyn M., et al. "Neuropsychological profiles and descriptive classifications of mass murderers." Aggression and violent behavior 30 (2016): 94104; Gerard, F. Jeane, et al. "Offender and offence characteristics of school shooting incidents." Journal of Investigative Psychology and Offender Profiling 13.1 (2016): 22-38; Gill et al., 2016; Langman, Peter. "Rampage school shooters: A typology." Aggression and Violent behavior 14.1 (2009): 79-86; Lankford, 2013, 2016; Taylor, 2018.

24. Declercq, Frederic, and Kurt Audenaert. "A case of mass murder: Personality disorder, psychopathology and violence mode." Aggression and Violent Behavior 16.2 (2011): 135-143; Fox, James Alan, and Jack Levin. "Firing back: The 
growing threat of workplace homicide." The Annals of the American Academy of Political and Social Science 536.1 (1994): 16-30; Hempel, Anthony G., and T. C. Richards. "Offender and offense characteristics of a nonrandom sample of mass murderers." Journal of the American Academy of Psychiatry and the Law Online 27.2 (1999): 213-225; Levin, Jack, and Eric Madfis. "Mass murder at school and cumulative strain: A sequential model." American behavioral scientist 52.9 (2009): $1227-1245$.

25. Levin \& Madfis, 2009; Silver, Horgan, \& Gill, 2019

26. DeLisi, Matt, and Aaron M. Scherer. "Multiple homicide offenders: Offense characteristics, social correlates, and criminal careers." Criminal Justice and Behavior 33.3 (2006): 367-391.

27. Fox et al., (2016)

28. Gill, Paul. Lone-actor terrorists: A behavioural analysis. Routledge, 2015; Gill, Paul, John Horgan, and Paige Deckert. "Bombing alone: Tracing the motivations and antecedent behaviors of lone-actor terrorists." Journal of forensic sciences 59.2 (2014): 425-435; Hamm, Mark S., and Ramón Spaaij. The age of lone wolf terrorism. Columbia University Press, 2017; Horgan, John, et al. "Actions speak louder than words: A behavioral analysis of 183 individuals convicted for terrorist offenses in the United States from 1995 to 2012." Journal of forensic sciences 61.5 (2016): 12281237; Meloy, J. Reid, and Paul Gill. "The lone-actor terrorist and the TRAP18." Journal of Threat Assessment and Management3.1 (2016): 37; Sageman, Marc. Leaderless jihad: Terror networks in the twenty-first century. University of Pennsylvania Press, 2011; Spaaij, Ramón. "The enigma of lone wolf terrorism: An assessment." Studies in Conflict \& Terrorism 33.9 (2010): 854-870.

29. Silver et al. 2019 
30. Lankford (2013)

31. McCauley, Clark, Sophia Moskalenko, and Benjamin Van Son. "Characteristics of lone-wolf violent offenders: A comparison of assassins and school attackers." Perspectives on Terrorism7.1 (2013): 4-24.

32. Böckler et al. (2018)

33. Meloy, J. Reid, et al. "Offender and offense characteristics of a nonrandom sample of adolescent mass murderers." Journal of the American Academy of Child \& Adolescent Psychiatry 40.6 (2001): 719-728.

34. Levin \& Madfis, 2009

35. Gill et al., 2016

36. Taylor, 2018

37. Bouhana et al. (2016); Corner et al. (2018)

38. Böckler et al., 2018; Bouhana et al., 2018; Capellan et al., 2018; Ferguson et al., 2011; Fox \& Levin, 1994; Gerard et al., 2016; Gill, 2015; Gill et al., 2014; Levin \& Madfis, 2009; Meloy \& Gill, 2016; Newman, Katherine S., et al. Rampage: The social roots of school shootings. Hachette UK, 2008; Schuurman, Bart, et al. "Lone Actor Terrorist Attack Planning and Preparation: A Data-Driven Analysis." Journal of forensic sciences 63.4 (2018): 1191-1200.

39. Bouhana et al., 2018; Corner et al., 2019; Gill, et al., 2014; Lindekilde, Lasse, Francis O’Connor, and Bart Schuurman. "Radicalization patterns and modes of attack planning and preparation among lone-actor terrorists: an exploratory analysis." Behavioral Sciences of Terrorism and Political Aggression 11.2 (2019): 113-133; Meloy \& Gill, 2016; Schuurman et al. 2018; Smith, Brent L., et al. "The emergence of lone wolf terrorism: Patterns of behavior and implications for 
intervention." Terrorism and counterterrorism today. Emerald Group Publishing Limited, 2015. 89-110.

40. Allwinn, Mirko, Jens Hoffmann, and J. Reid Meloy. "German mass murderers and their proximal warning behaviors." Journal of Threat Assessment and Management 6.1 (2019): 1.; Fox \& Levin, 2003; Gill, Silver, Horgan, \& Corner, 2017; Meloy, J. Reid. "Empirical basis and forensic application of affective and predatory violence." Australian and New Zealand Journal of Psychiatry 40.6-7 (2006): 539-547; Meloy, J. Reid. "The seven myths of mass murder." Violence and Gender 1.3 (2014): 102-104; Silver, Horgan \& Gill, 2019

41. Capellan, 2015; Horgan, Gill, et al., 2016

42. Bouhana et al., 2018; Gill et al., 2014; Gill et al., 2016; Horgan, Gill, et al., 2016; Horgan, Shortland, et al., 2016; Lankford, 2018; Meloy, J. Reid, et al. "Some warning behaviors discriminate between school shooters and other students of concern." Journal of Threat Assessment and Management 1.3 (2014): 203;

Schuurman et al., 2018; Silver, Horgan, \& Gill, 2018

43. Bouhana et al., 2018; Gill \& Horgan, 2012; Hamm \& Spaaij, 2017; Hofmann, David C. "How "Alone" are Lone-Actors? Exploring the Ideological, Signaling, and Support Networks of Lone-Actor Terrorists." Studies in Conflict \& Terrorism (2018): 1-22.; Schuurman et al., 2018; Spaaij, 2010

44. Schuurman et al., 2019

45. Malthaner, Stefan, and Lasse Lindekilde. "Analyzing pathways of lone-actor radicalization: A relational approach." Constructions of Terrorism: An Interdisciplinary Approach to Research and Policy (2017): 163-180.

46. Stefanska, Ewa B., et al. "Offense pathways of non-serial sexual killers." Journal of Criminal Justice 43.2 (2015): 99-107. 
47. Horan, Loren, and Eric Beauregard. "Pathways in the offending process of sex offenders who target marginalised victims." Journal of investigative psychology and offender profiling 14.3 (2017): 213-226.

48. Proulx, Jean, and Eric Beauregard. "Pathways in the offending process of extrafamilial sexual aggressors against women." Pathways to sexual aggression. Routledge, 2014. 85-123.

49. Leclerc, B., Beauregard, E., Forouzan, E., \& Proulx, J. (2014). Offending pathways of intrafamilial child sex offenders. In Pathways to Sexual Aggression (pp. 156-178). London, England: Routledge.

50. Brouillette-Alarie, Sébastien, and Jean Proulx. "An exploratory analysis of the offending process of extrafamilial sexual aggressors against adolescents." Pathways to sexual aggression (2014): 179-200.

51. Proulx and Beauregard (2014).

52. Bryanna Hahn, and David P. Farrington. "Creating burglary profiles using latent class analysis: A new approach to offender profiling." Criminal Justice and Behavior 39.12 (2012): 1582-1611.

53. Pedneault, Amélie, Danielle A. Harris, and Raymond A. Knight. "Toward a typology of sexual burglary: Latent class findings." Journal of Criminal Justice 40.4 (2012): 278-284.

54. Cosden, Merith, et al. "Trauma symptoms for men and women in substance abuse treatment: A latent transition analysis." Journal of substance abuse treatment 50 (2015): 18-25.

55. Krishnakumar, Ambika, Nicole Conroy, and Lutchmie Narine. "Correlates of sexspecific young adult college student dating violence typologies: A latent class analysis approach." Psychology of violence 8.2 (2018): 151. 
56. Clemmow et al., 2019

57. Ibid

58. Corner et al., 2019

59. Horgan, Gill, et al., 2016

60. Silver, Horgan, \& Gill, 2018; Sageman, 2004

61. Freilich, Joshua D., et al. "Patterns of fatal extreme-right crime in the United States." Perspectives on Terrorism 12.6 (2018): 38-51.

62. See Clemmow et al. (2019)

63. DeLisi, Matt, and Aaron M. Scherer. "Multiple homicide offenders: Offense characteristics, social correlates, and criminal careers." Criminal Justice and Behavior 33.3 (2006): 367-391.

64. Gill et al. 2016

65. Declercq, Frédéric, and Kurt Audenaert. "Predatory violence aiming at relief in a case of mass murder: Meloy's criteria for applied forensic practice." Behavioral sciences \& the law 29.4 (2011): 578-591; Meloy, J. Reid. The psychopathic mind: Origins, dynamics, and treatment. Rowman \& Littlefield, 1988.

66. Böckler et al., 2018; Bouhana et al., 2018; Capellan et al., 2018; Ferguson et al., 2011; Fox \& Levin, 1994; Gerard et al., 2016; Gill et al., 2014; Levin \& Madfis, 2009; Meloy \& Gill, 2016; Newman et al., 2008; Schuurman et al., 2018

67. Dutton, Donald G., Katherine R. White, and Dan Fogarty. "Paranoid thinking in mass shooters." Aggression and Violent Behavior 18.5 (2013): 548-553.

68. Knoll, James L., and J. Reid Meloy. "Mass murder and the violent paranoid spectrum." Psychiatric Annals 44.5 (2014): 236-243.

69. Meloy, J. Reid. "The seven myths of mass murder." Violence and Gender 1.3 (2014): 102-104. 
70. Hempel \& Richards (1999); Knoll \& Meloy, 2014 Meloy, J. Reid. "Predatory violence during mass murder." Journal of Forensic Science 42.2 (1997): 326-329.

71. Bouhana et al., 2018; Gill, 2015; Gill et al., 2014

72. Clemmow et al. 2019

73. Meloy, J. Reid, and Mary Ellen O'toole. "The concept of leakage in threat assessment." Behavioral sciences \& the law29.4 (2011): 513-527.

74. Clemmow et al., 2019; Corner et al. 2018

75. Böckler, Nils, et al. "School shootings: Conceptual framework and international empirical trends." School shootings. Springer, New York, NY, 2013. 1-24.

76. Capellan, 2015; Gruenewald, 2011; Gruenewald, Chermak, \& Freilich, 2013; Gruenewald, Chermak, \& Freilich, 2013; Gruenewald \& Pridemore, 2012; Lankford, 2013

77. Bouhana et al, 2016; 2018

78. Neo, Loo Seng, et al. "Developing an early screening guide for jihadi terrorism: A behavioural analysis of 30 terror attacks." Security Journal 30.1 (2017): 227-246; Precht, Tomas. "Homegrown terrorism and Islamist radicalisation in Europe: From conversion to terrorism." Danish Ministry of Defense (2007); Silber, Mitchell D., Arvin Bhatt, and Senior Intelligence Analysts. Radicalization in the West: The homegrown threat. New York: Police Department, 2007; Wiktorowicz, Quintan, ed. Islamic activism: A social movement theory approach. Indiana University Press, 2004.

79. McCauley, Clark, and Sophia Moskalenko. "Mechanisms of political radicalization: Pathways toward terrorism." Terrorism and political violence 20.3 (2008): 415-433.

80. Declercq, Frédéric, and Kurt Audenaert. "Predatory violence aiming at relief in a case of mass murder: Meloy's criteria for applied forensic practice." Behavioral sciences \& 
the law 29.4 (2011): 578-591; Meloy, J. Reid. "Empirical basis and forensic application of affective and predatory violence." Australian and New Zealand Journal of Psychiatry 40.6-7 (2006): 539-547.

81. Levin and Madfis (2009)

82. Bouhana et al, 2016).

83. Safer-Lichtenstein, Aaron, Gary LaFree, and Thomas Loughran. "Studying terrorism empirically: What we know about what we don't know." Journal of contemporary criminal justice 33.3 (2017): 273-291.

84. Spaaij \& Hamm, 2015

85. Gill, 2015; Gill \& Horgan, 2012; Gill et al., 2016; Gruenewald et al., 2013; Horgan, Gill, et al., 2016; Silver et al., 2018, 2019; Taylor, 2018

86. Gill, Paul, et al. "What Do Closed Source Data Tell Us About Lone Actor Terrorist Behavior? A Research Note." Terrorism and Political Violence (2019): 1-18.

87. Gill, Paul, et al. "Terrorist use of the Internet by the numbers: Quantifying behaviors, patterns, and processes." Criminology \& Public Policy 16.1 (2017): 99-117.

88. Fein, Robert A., and Bryan Vossekuil. "Assassination in the United States: An operational study of recent assassins, attackers, and near-lethal approachers." Journal of Forensic Science 44.2 (1999): 321-333; Gill et al., 2014; Gruenewald et al., 2013; Vossekuil, B. "The Final Report and Findings of the Safe School Initiative: Implications for the Prevention of School Attacks in the United States. Darby." (2002).

89. Gill, Paul, et al. "Indicators of lone actor violent events: The problems of low base rates and long observational periods." Journal of Threat Assessment and Management 3.3-4 (2016): 165. 
90. Lloyd, Monica, and Christopher Dean. "The development of structured guidelines for assessing risk in extremist offenders." Journal of Threat Assessment and Management 2.1 (2015): 40.

91. Pressman, Ellen, et al. "VERA-2R Violent Extremism Risk Assessment Version 2 Revised: a Structured Professional Judgement Approach." Utrecht, The Netherlands: NIFP/DJI(2016).

92. Van Dyke, Russell B., and Jennifer L. Schroeder. "Implementation of the Dallas Threat of Violence Risk Assessment." (2006).

93. Clemmow et al., 2019; Corner, et al., 2018; Schuurman, Bakker, Gill, \& Bouhana 2017

94. Borum, Randy, et al. "What can be done about school shootings? A review of the evidence." Educational Researcher39.1 (2010): 27-37; Capellan, Joel A., and Carla Lewandowski. "Can threat assessment help police prevent mass public shootings? Testing an intelligence-led policing tool." Policing: An International Journal 42.1 (2019): 16-30; Lloyd \& Dean, 2015; Meloy, J. Reid, et al. "The concept of identification in threat assessment." Behavioral Sciences \& the Law 33.2-3 (2015): 213-237; Vossekuil, Bryan, Robert A. Fein, and John M. Berglund. "Threat assessment: Assessing the risk of targeted violence." Journal of Threat Assessment and Management 2.3-4 (2015): 243.

95. Borum, R., P. A. Bartel, and A. E. Forth. "Mental health screening and assessment in juvenile justice." T. Grisso, G. Vincent, \& D. Seagrave (Eds.) (2005): 311-323.

96. White, S. Meloy. "JR (2007)." Manual for the Workplace Assessment of Violence Risk (WAVR-21). San Diego, CA: Specialized Training Services.

97. Mohandie, K. R. I. S. "Threat assessment in schools." International handbook of threat assessment (2014): 126-141. 
98. Meloy and O'Toole (2011)

99. Meloy \& Gill, 2016

100. Capellan \& Lewandowski, 2019; McGarrell, Edmund F., Joshua D. Freilich, and Steven Chermak. "Intelligence-led policing as a framework for responding to terrorism." Journal of Contemporary Criminal Justice 23.2 (2007): 142-158

101. Capellan and Lewandowski (2019)

102. Ratcliffe, Jerry H., and Ray Guidetti. "State police investigative structure and the adoption of intelligence-led policing." Policing: An International Journal of Police Strategies \& Management 31.1 (2008): 109-128.

103. Walby, Kevin, and Jeff Monaghan. "Policing Proliferation: On Militarization and Atomic Energy Canada Limited's Nuclear Response Forces." Canadian Journal of Criminology and Criminal Justice 52.2 (2010): 117-145; Pathé, Michele T., et al. "Establishing a joint agency response to the threat of LAGFV." The Journal of Forensic Psychiatry \& Psychology 29.1 (2018): 37-52.

104. Carter, David L., et al. "Understanding the intelligence practices of state, local, and tribal law enforcement agencies." (2011).

105. Ibid

106. Carter, Jeremy G., et al. "Law enforcement fusion centers: Cultivating an information sharing environment while safeguarding privacy." Journal of Police and Criminal Psychology 32.1 (2017): 11-27.

107. DHS 2019

108. Leitan \& Sheehan, 2018 
Table 1. Prevalence of propensity factors by cluster membership

\begin{tabular}{lccc}
\hline & Criminal & Stable & Unstable \\
Propensity factors & $n=64$ & $n=55$ & $n=64$ \\
\hline Criminal convictions & $\mathbf{1 0 0 . 0 0 \%}$ & $25.50 \%$ & $\mathbf{9 . 4 0 \%}$ \\
Chronic stress & $53.10 \%$ & $\mathbf{0 . 0 0 \%}$ & $\mathbf{9 2 . 2 0 \%}$ \\
Previously imprisoned & $\mathbf{7 1 . 9 0 \%}$ & $\mathbf{7 . 3 0 \%}$ & $\mathbf{1 . 6 0 \%}$ \\
Previous military experience & $9.40 \%$ & $\mathbf{2 9 . 1 0 \%}$ & $1.60 \%$ \\
Unemployed & $35.90 \%$ & $\mathbf{1 0 . 9 0 \%}$ & $48.40 \%$ \\
Juvenile arrest & $\mathbf{2 0 . 3 0 \%}$ & $1.80 \%$ & $3.10 \%$ \\
Mental illness & $40.60 \%$ & $32.70 \%$ & $67.20 \%$ \\
University experience & $\mathbf{1 2 . 5 0 \%}$ & $36.40 \%$ & $43.80 \%$ \\
Rejected from military & $4.70 \%$ & $5.50 \%$ & $\mathbf{2 5 . 0 0 \%}$ \\
Socially isolated & $21.90 \%$ & $31.90 \%$ & $51.60 \%$ \\
Children & $42.20 \%$ & $25.50 \%$ & $17.20 \%$ \\
Exceptional educationally & $1.60 \%$ & $18.20 \%$ & $15.60 \%$ \\
Married & $21.90 \%$ & $20.00 \%$ & $9.40 \%$ \\
History of substance abuse & $46.90 \%$ & $30.90 \%$ & $37.50 \%$ \\
Combat experience & $7.80 \%$ & $7.30 \%$ & $1.60 \%$ \\
Born outside of US & $17.20 \%$ & $27.30 \%$ & $28.10 \%$ \\
\hline
\end{tabular}


Table 2. Prevalence of situational factors by cluster membership.

\begin{tabular}{|c|c|c|c|}
\hline Situational factors & $\begin{array}{l}\text { Low stress } \\
\qquad n=83\end{array}$ & $\begin{array}{l}\text { High stress } \\
\begin{array}{l}\text { (social) } \\
n=67\end{array}\end{array}$ & $\begin{array}{c}\text { High stress } \\
\text { (interpersonal) } \\
n=33\end{array}$ \\
\hline Ignored & $0.0 \%$ & $19.4 \%$ & $84.8 \%$ \\
\hline Not cared for & $0.0 \%$ & $17.9 \%$ & $81.8 \%$ \\
\hline Injustice/prejudice & $10.0 \%$ & $68.7 \%$ & $6.1 \%$ \\
\hline Tipping point & $25.3 \%$ & $89.6 \%$ & $30.3 \%$ \\
\hline Degraded & $9.6 \%$ & $65.7 \%$ & $18.2 \%$ \\
\hline Disrespected & $9.6 \%$ & $65.7 \%$ & $18.2 \%$ \\
\hline Problematic relationships & $24.1 \%$ & $59.7 \%$ & $93.9 \%$ \\
\hline Escalating anger & $24.5 \%$ & $62.7 \%$ & $18.2 \%$ \\
\hline Recent stressor & $27.7 \%$ & $80.6 \%$ & $54.5 \%$ \\
\hline Experienced being a helpless victim & $6.0 \%$ & $41.8 \%$ & $0.0 \%$ \\
\hline Angry & $45.8 \%$ & $91.0 \%$ & $63.6 \%$ \\
\hline Recently unemployed & $14.5 \%$ & $58.2 \%$ & $45.5 \%$ \\
\hline Financial problems & $24.5 \%$ & $53.7 \%$ & $39.4 \%$ \\
\hline Work stressor & $20.5 \%$ & $61.2 \%$ & $42.4 \%$ \\
\hline Proximate life change & $8.4 \%$ & $25.4 \%$ & $9.1 \%$ \\
\hline Lived alone at the time of event & $19.3 \%$ & $41.9 \%$ & $34.4 \%$ \\
\hline Victim of verbal/physical abuse & $12.0 \%$ & $23.9 \%$ & $6.1 \%$ \\
\hline Promise broken & $1.2 \%$ & $9.0 \%$ & $12.1 \%$ \\
\hline Dropped out of school & $6.0 \%$ & $16.4 \%$ & $18.2 \%$ \\
\hline Family death & $12.0 \%$ & $6.0 \%$ & $22.1 \%$ \\
\hline
\end{tabular}


Table 3. Prevalence of preparatory indicators by cluster membership.

\begin{tabular}{lcccccc}
\hline & Novel & & & & & \\
& aggressio & Predator & Clandesti & Preparat & & Equippe \\
& $\mathrm{n}$ & $\mathrm{y}$ & $\mathrm{ne}$ & ory & Fixated & $\mathrm{d}$ \\
Preparatory indicators & $n=36$ & $n=34$ & $n=26$ & $n=33$ & $n=31$ & $n=23$ \\
\hline Obsessed with an event & $\mathbf{0 . 0 \%}$ & $\mathbf{1 4 . 7 \%}$ & $\mathbf{3 . 8 \%}$ & $\mathbf{6 3 . 6 \%}$ & $\mathbf{1 0 0 . 0 \%}$ & $\mathbf{0 . 0 \%}$ \\
Stockpiled weapons & $\mathbf{0 . 0 \%}$ & $\mathbf{6 1 . 8 \%}$ & $\mathbf{0 . 0 \%}$ & $54.5 \%$ & $22.3 \%$ & $\mathbf{1 0 0 . 0 \%}$ \\
Novel aggression & $\mathbf{5 5 . 6 \%}$ & $\mathbf{9 7 . 1 \%}$ & $\mathbf{3 . 8 \%}$ & $24.2 \%$ & $\mathbf{2 5 . 2 \%}$ & $\mathbf{0 . 0 \%}$ \\
Travelled to prepare & $0.0 \%$ & $\mathbf{0 . 0 \%}$ & $3.8 \%$ & $\mathbf{4 8 . 5 \%}$ & $6.5 \%$ & $\mathbf{0 . 0 \%}$ \\
Address change & $\mathbf{0 . 0 \%}$ & $61.8 \%$ & $\mathbf{9 2 . 3 \%}$ & $69.7 \%$ & $41.9 \%$ & $52.2 \%$ \\
Hands-on training & $2.8 \%$ & $2.9 \%$ & $7.7 \%$ & $\mathbf{5 4 . 5 \%}$ & $\mathbf{3 . 2 \%}$ & $17.4 \%$ \\
Dry-runs & $\mathbf{0 . 0 \%}$ & $23.5 \%$ & $11.5 \%$ & $\mathbf{3 9 . 4 \%}$ & $\mathbf{0 . 0 \%}$ & $\mathbf{0 . 0 \%}$ \\
History with location & $69.4 \%$ & $47.1 \%$ & $65.4 \%$ & $\mathbf{3 9 . 4 \%}$ & $\mathbf{1 0 0 . 0 \%}$ & $47.8 \%$ \\
Cleared bank account & $2.8 \%$ & $0.0 \%$ & $\mathbf{2 3 . 1 \%}$ & $9.1 \%$ & $3.2 \%$ & $13.0 \%$ \\
Sought legitimisation & $0.0 \%$ & $\mathbf{1 4 . 7 \%}$ & $3.8 \%$ & $9.1 \%$ & $0.0 \%$ & $0.0 \%$ \\
Altered appearance & $0.0 \%$ & $5.9 \%$ & $15.4 \%$ & $3.0 \%$ & $\mathbf{0 . 0 \%}$ & $9.7 \%$ \\
Substance use pre-event & $19.4 \%$ & $14.7 \%$ & $0.0 \%$ & $9.1 \%$ & $16.1 \%$ & $26.1 \%$ \\
\hline
\end{tabular}


Table 4. Prevalence of leakage indicators by cluster membership.

\begin{tabular}{lcc}
\hline & $\begin{array}{c}\text { High } \\
\text { leakage }\end{array}$ & $\begin{array}{c}\text { Low } \\
\text { leakage } \\
\text { Leakage indicators }\end{array}$ \\
\hline Others aware of grievances & $\mathbf{8 6 . 2 \%}$ & $\mathbf{0 . 0 \%}$ \\
Verbal statements to friends/family & $\mathbf{6 0 . 2 \%}$ & $\mathbf{1 . 7 \%}$ \\
Verbal statements to wider audience & $\mathbf{5 6 . 1 \%}$ & $\mathbf{0 . 0 \%}$ \\
Expressed a desire to hurt others & $\mathbf{7 4 . 0 \%}$ & $\mathbf{1 8 . 3 \%}$ \\
Others aware of their ideology & $\mathbf{3 9 . 8 \%}$ & $\mathbf{0 . 0 \%}$ \\
Produced letters & $44.7 \%$ & $3.3 \%$ \\
Gave an event-specific warning & $32.5 \%$ & $0.0 \%$ \\
\hline
\end{tabular}


Table 5. Prevalence of network indicators by cluster membership.

\begin{tabular}{lccc}
\hline & Lone & Associated & Connected \\
Network indicators & $n=80$ & $n=66$ & $n=37$ \\
\hline Face-to-face interactions & $\mathbf{0 . 0 \%}$ & $\mathbf{4 . 5 \%}$ & $\mathbf{8 9 . 2 \%}$ \\
Joined a wider group & $0.0 \%$ & $\mathbf{0 . 0 \%}$ & $\mathbf{7 3 . 0 \%}$ \\
Engaged with group propaganda & $0.0 \%$ & $22.7 \%$ & $\mathbf{7 3 . 0 \%}$ \\
Claimed to be part of a wider group & $\mathbf{0 . 0 \%}$ & $22.1 \%$ & $\mathbf{6 2 . 2 \%}$ \\
Tried to recruit others & $0.0 \%$ & $4.5 \%$ & $\mathbf{3 5 . 1 \%}$ \\
Close associates criminal/violent & $\mathbf{0 . 0 \%}$ & $\mathbf{4 0 . 9 \%}$ & $37.8 \%$ \\
Others had knowledge of attack & $\mathbf{0 . 0 \%}$ & $\mathbf{3 9 . 4 \%}$ & $35.1 \%$ \\
Interacted virtually with others & $0.0 \%$ & $7.6 \%$ & $35.1 \%$ \\
Read propaganda by other offenders & $0.0 \%$ & $15.2 \%$ & $21.6 \%$ \\
Others involved in procuring weaponry & $0.0 \%$ & $\mathbf{1 6 . 7 \%}$ & $18.9 \%$ \\
Engaged with stories about other offenders & $\mathbf{0 . 0 \%}$ & $10.6 \%$ & $18.9 \%$ \\
Spouse involved & $0.0 \%$ & $6.1 \%$ & $13.5 \%$ \\
Command-and-control links & $0.0 \%$ & $0.0 \%$ & $5.4 \%$ \\
\hline
\end{tabular}




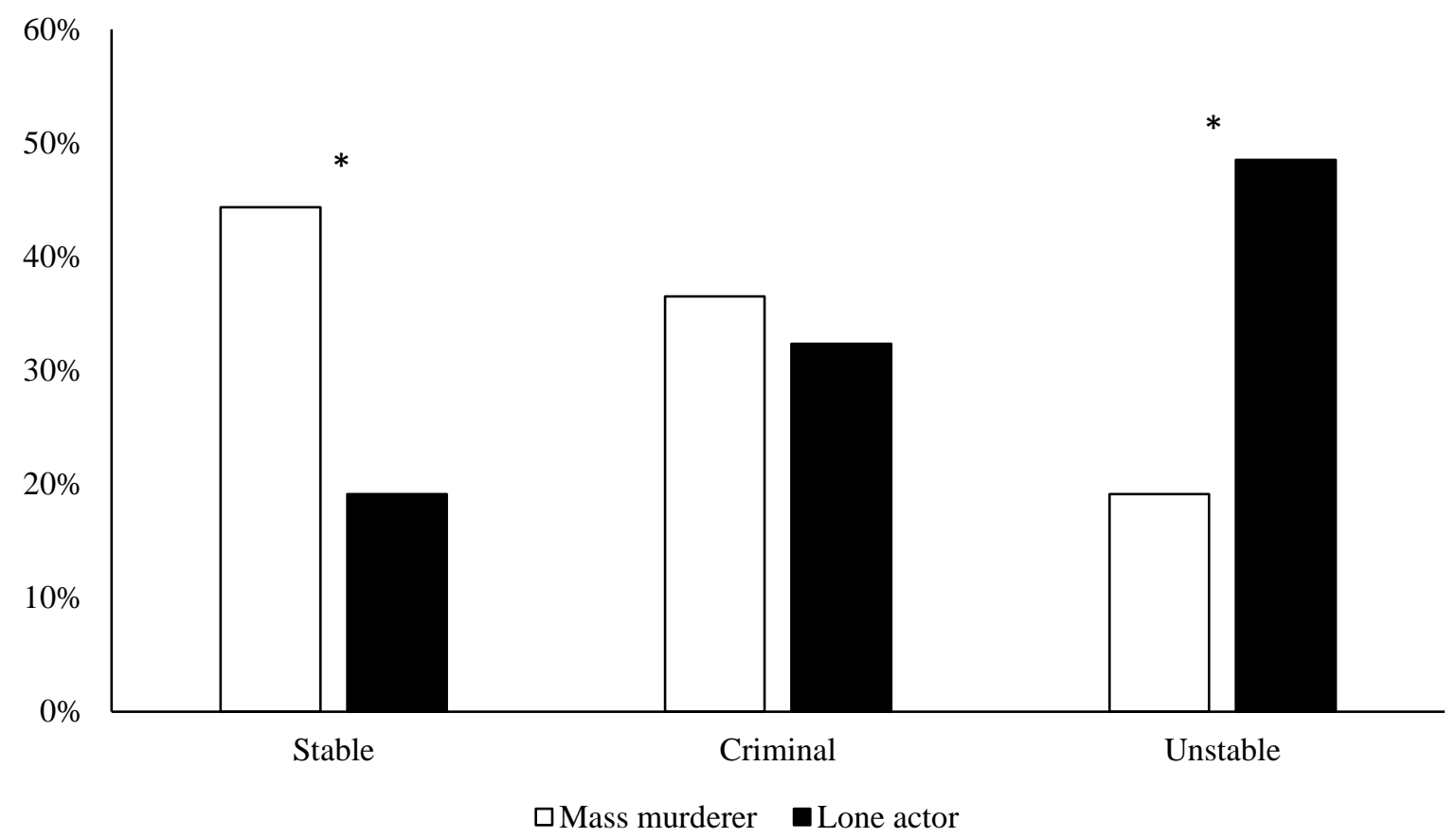

Figure 1. Percentage of offenders classified by propensity clusters. * significant difference between column proportions, $\mathrm{p}<.05$. 


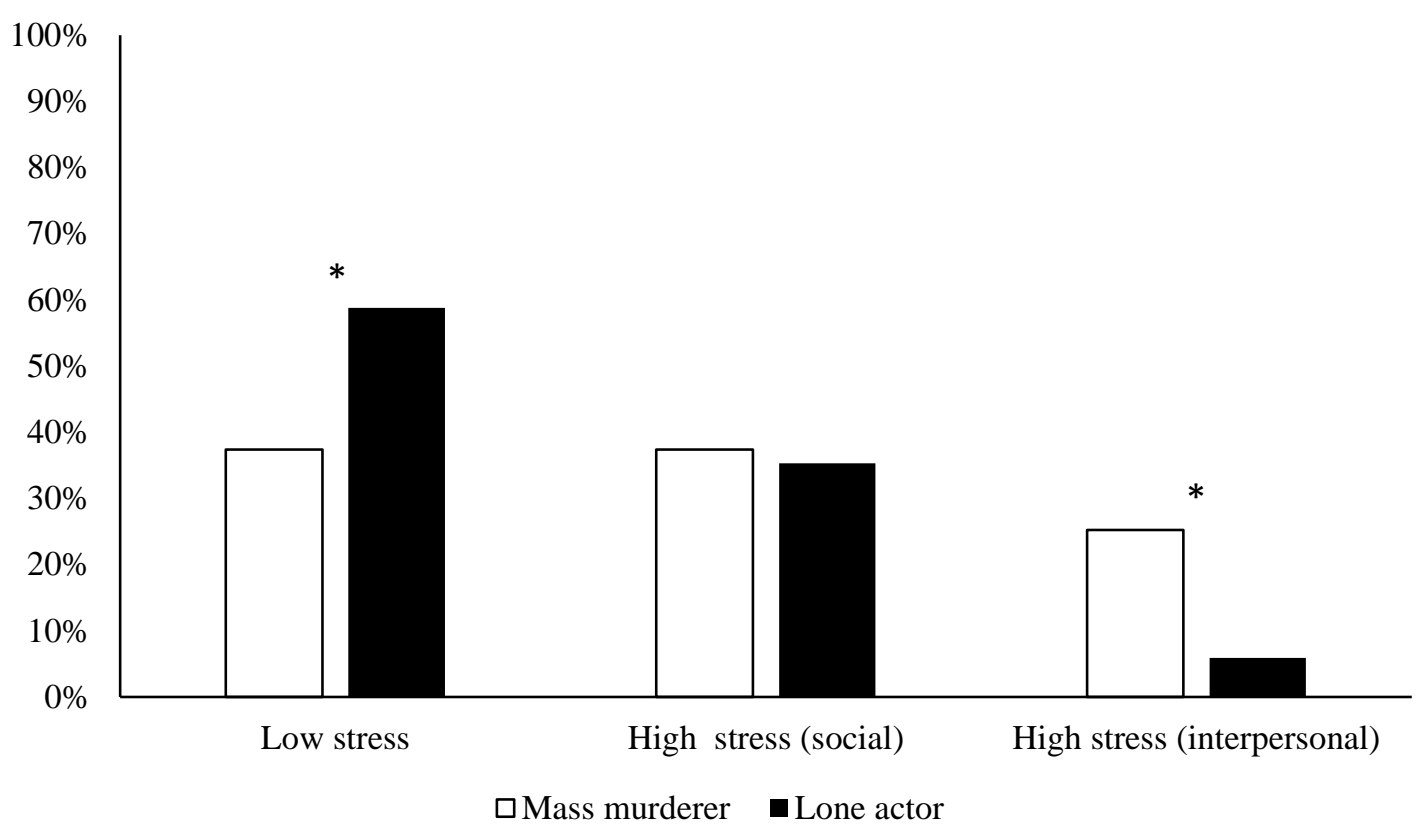

Figure 2. Percentage of offenders classified by situation clusters. * significant difference between column proportions, $\mathrm{p}<.05$. 


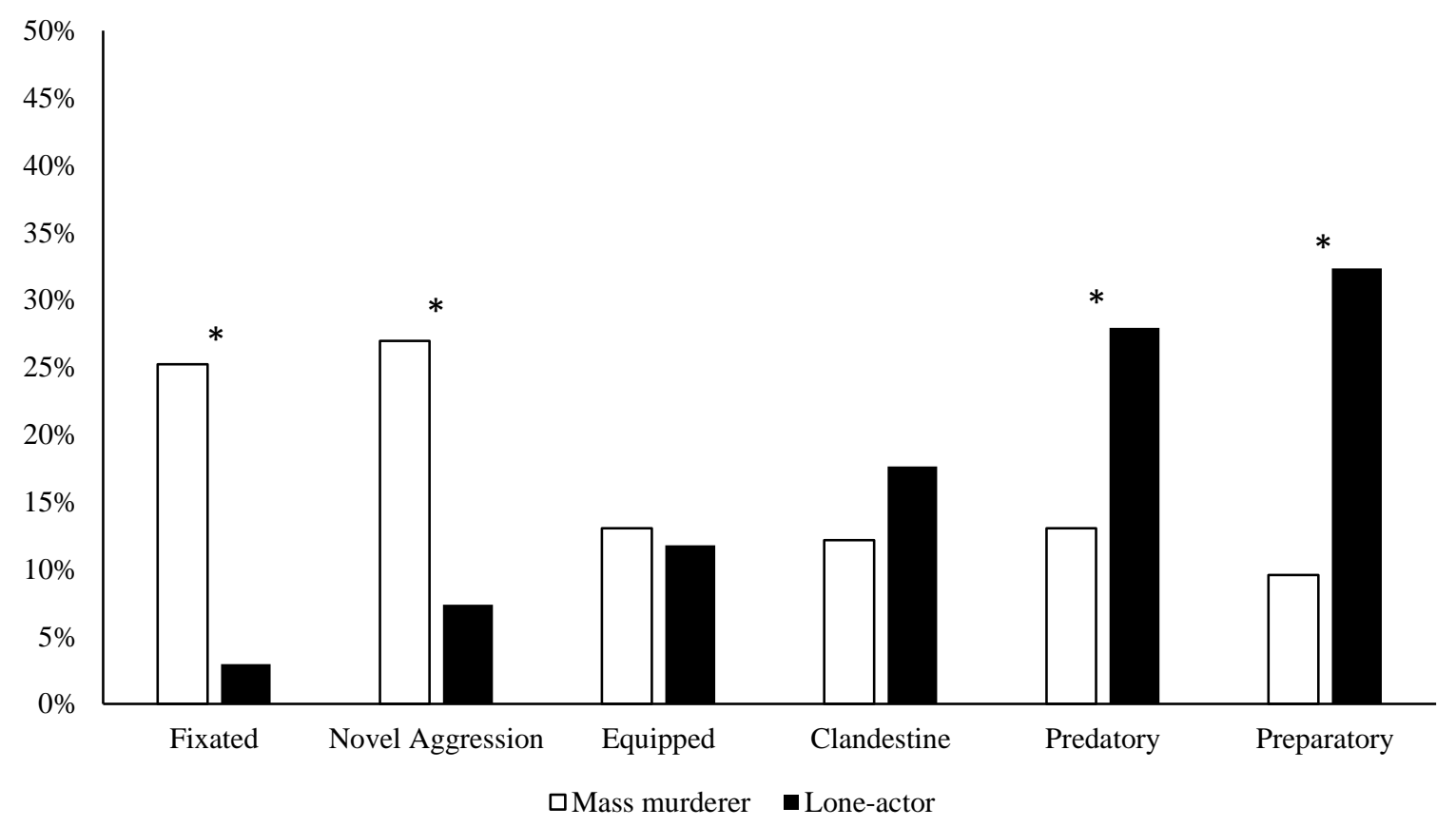

Figure 3. Percentage of offenders classified by preparatory clusters. * significant difference between column proportions, $\mathrm{p}<.05$. 


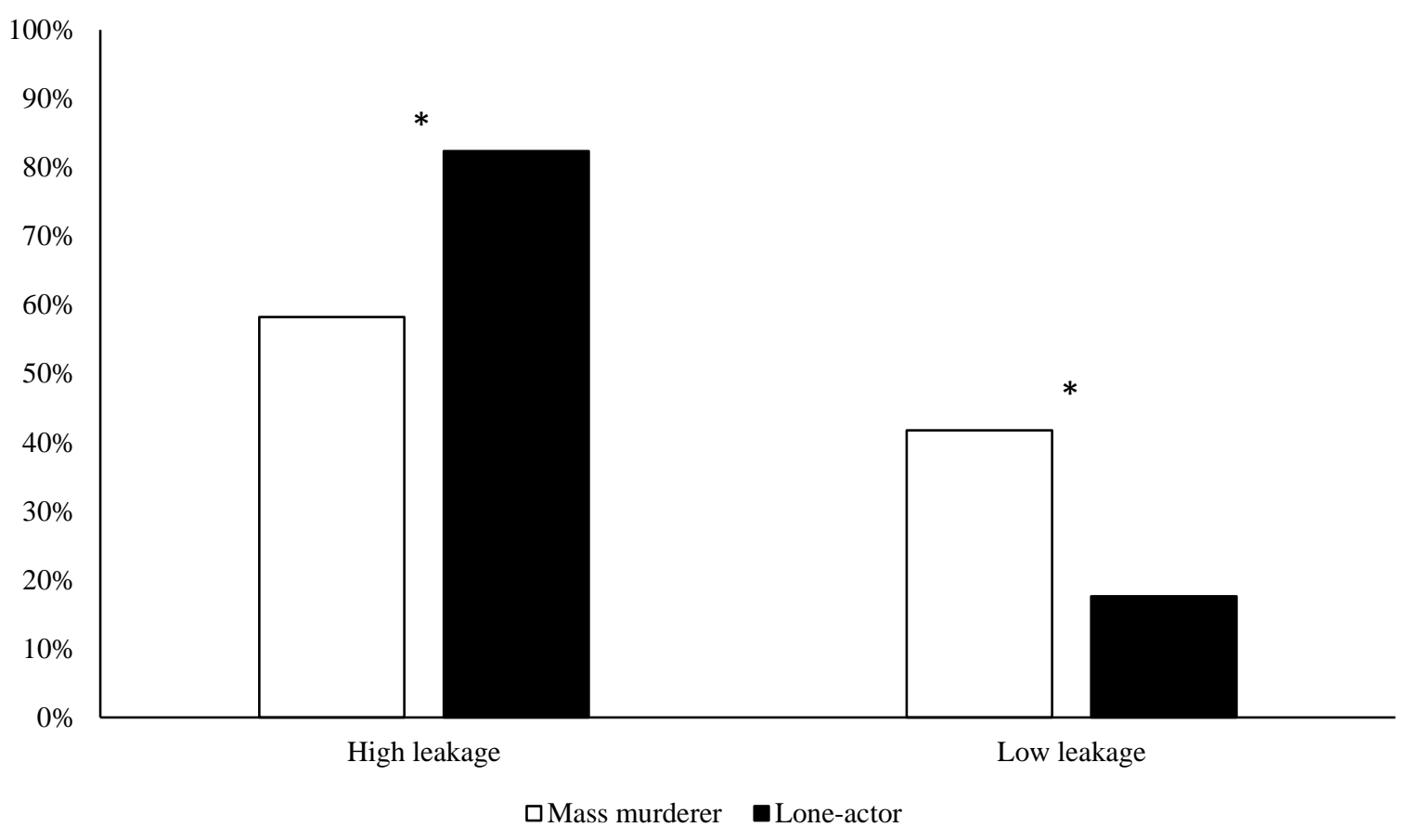

Figure 4. Percentage of offenders classified by leakage clusters. * significant difference between column proportions, $\mathrm{p}<.05$. 


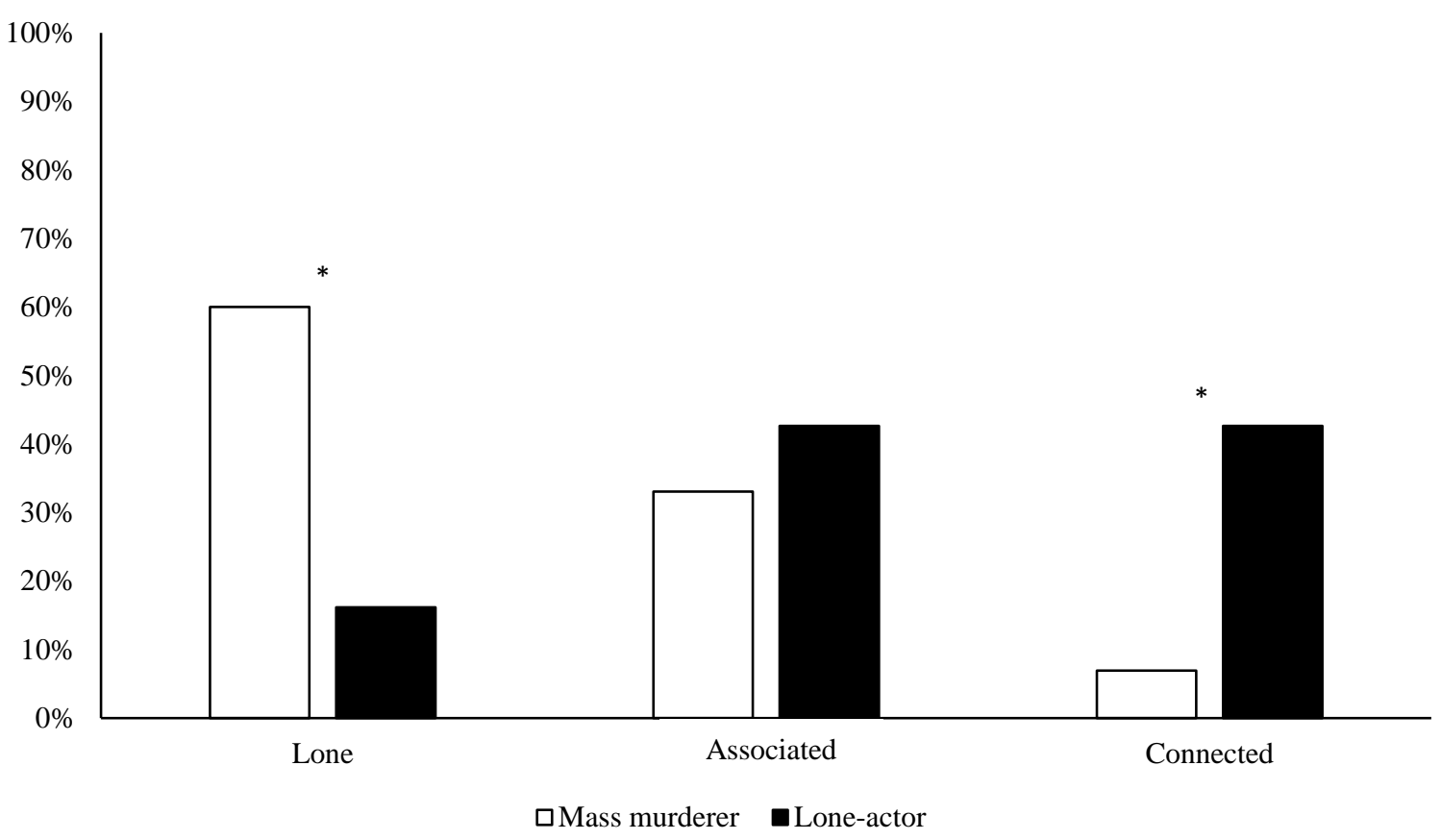

Figure 5. Percentage of offenders classified by network clusters. * significant difference between column proportions, $\mathrm{p}<.05$. 


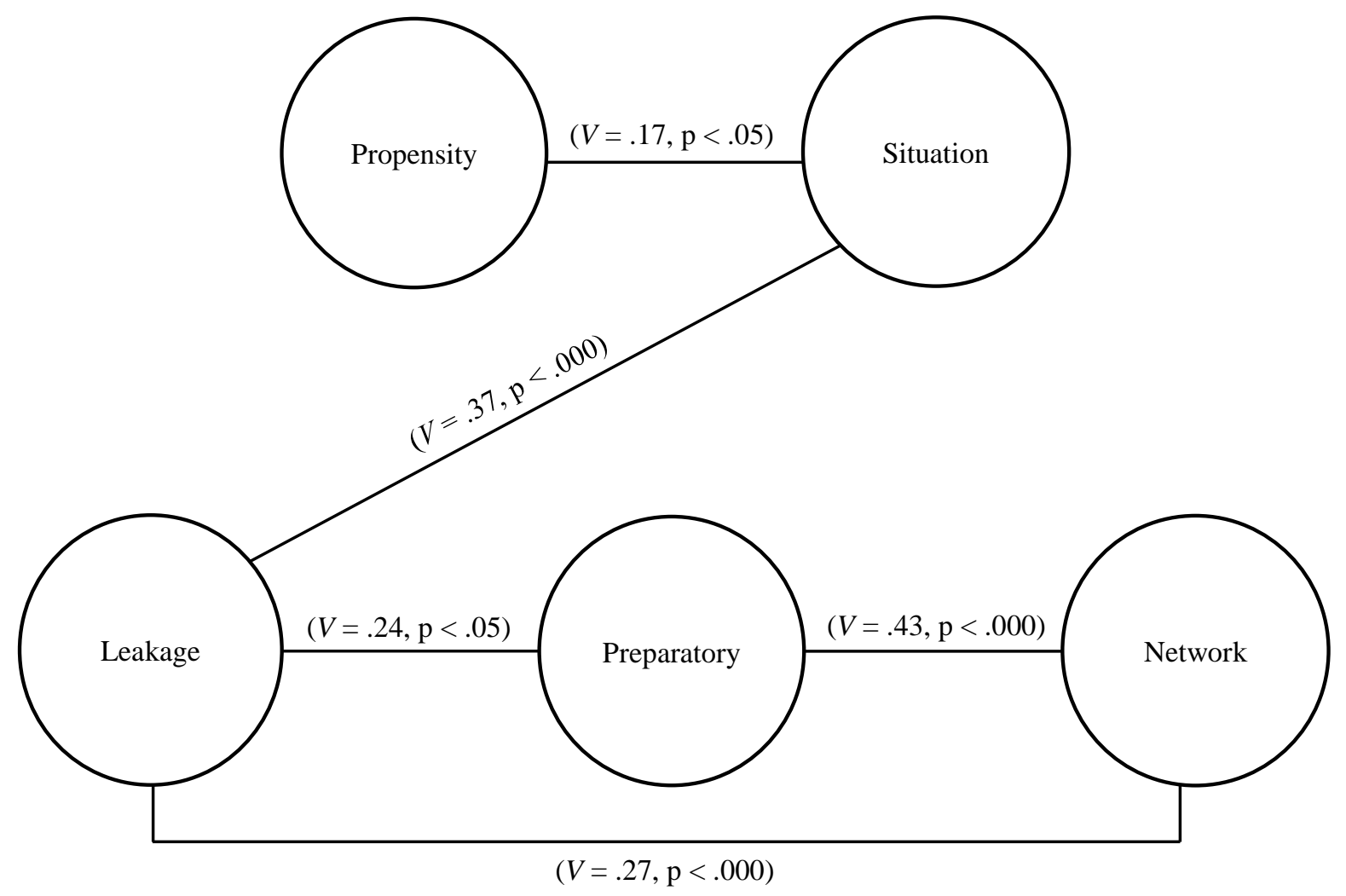

Figure 6. A model of LAGFV. Adjoining lines indicate a significant association. 